\title{
Malignant Fibrous Histiocytoma in the Parietal Bone
}

\section{-Case Report-}

\author{
Daizo YoshidA, Katsuyuki HARASHIMA, Yoji NODE, Toyoyuki KOJIMA, \\ Toshiro SHIMURA, and Akira TERAMOTO
}

Department of Neurosurgery, Nippon Medical School, Tokyo

\begin{abstract}
Malignant fibrous histiocytomas (MFHs) are mesenchymal tumors, usually arising in soft tissue of the extremities and are remarkably resistant to radiation and chemotherapy. A 45-year-old female presented with a rare case of MFH originating in the cranial bone manifesting as a lump in the left parietal region with no neurological abnormality. Neuroimaging revealed the presence of an osteolytic tumor in the left parietal bone invading into muscle and subdural region, penetrating through the dura. Selective external carotid angiography disclosed a marked tumor stain. Examination of the whole body excluded neoplastic disease elsewhere. The patient was treated by surgical excision, radiation, and two courses of multi-drug chemotherapy using cyclophosphamide, doxorubicin, vincristine, and prednisolone. Since there is no established treatment against this malignancy, a longer follow-up is necessary to determine whether cure has been achieved.
\end{abstract}

Key words: malignant fibrous histiocytoma, parietal bone, skull tumor

\section{Introduction}

Malignant fibrous histiocytoma (MFH) is a pleomorphic high grade sarcoma, commonly arising from the extremities and retroperitoneum and is the most common soft tissue sarcoma of late adult life. ${ }^{11)}$ Most MFHs occur in males and mainly in the third to sixth decades of life. The sites of primary osseous involvement vary, but the long bones of the lower extremities are most common. ${ }^{2)} \mathrm{MFH}$ is relatively rare in the head and neck region, where only $1 \%$ to $3 \%$ of cases of MFH are located. ${ }^{15]}$ The maxilla and the mandible are the most frequently involved. ${ }^{73} \mathrm{~A}$ calvarial origin for this lesion is very rare.

We describe a case of $\mathrm{MFH}$ in the left parietal region treated by surgery, radiotherapy, and chemotherapy.

\section{Case Report}

A 45-year-old female was referred for neurosurgical consultation in October 1994 because of a lump in the left parietal region persisting for approximately 4 weeks. The lump was not painful, but had in-

Received September 17, 1997; Accepted February 26, 1998 creased progressively in size.

Radiography of the skull showed left parietal bone destruction suggesting the presence of the skull abnormality (Fig. 1). She was admitted to our hospital on November 15. On admission, the overlaying scalp was edematous, hyperemic, and exquisitely sensitive to touch. She had no neurological deficits.

Computed tomography [CT] revealed a subgaleal mass arising from the left parietal bone with bony erosion that was clearly apparent with both intracranial and subcutaneous extensions (Fig. 2). $\mathrm{T}_{1^{-}}$ weighted magnetic resonance (MR) imaging showed the tumor as low intensity and enhancement with gadolinium-diethylenetriaminepenta-acetic acid delineated the demarcation of the expansion toward the adjacent tissues. However, the tumor margin with the neighboring cortical surface was unclear (Fig. 3). These findings indicated tumor invasion into the brain. Selective external carotid angiography disclosed the vascular-rich skull tumor fed by the superficial temporal and meningeal medial arteries (Fig. 4). Scintigraphy with gallium demonstrated abnormal uptake in this lesion, but no uptake in the other organs. Tumor markers such as carcinoembryonic antigen, squamous cell carcinogenrelated antigen, and CA19-9 were absent in the serum. 


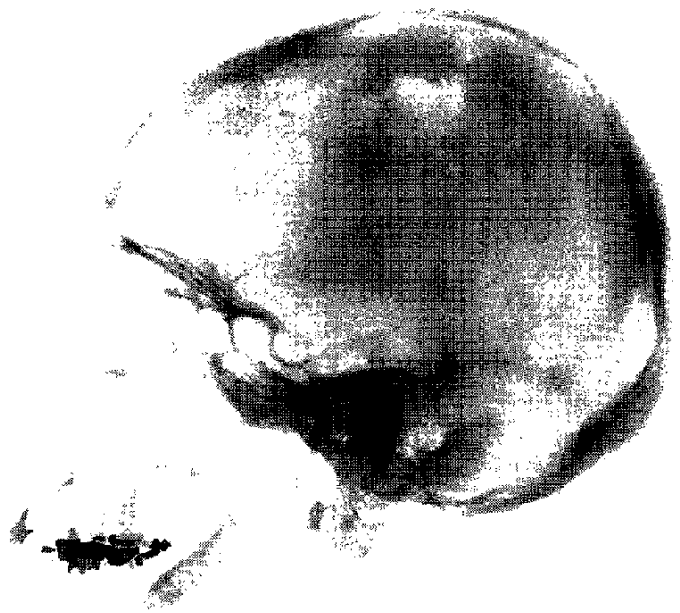

Fig. 1 Skull radiograph showing a radiolucent mass in the left parietal bone.

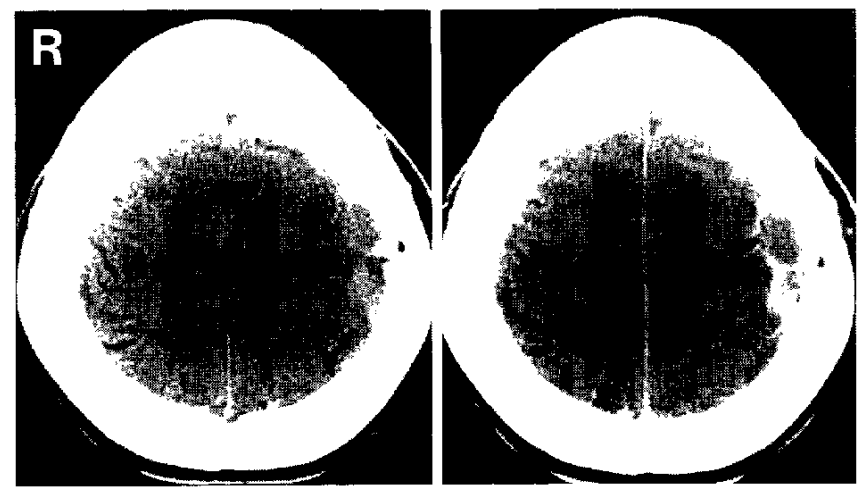

Fig. 2 Computed tomography scans without (left) and with (right) contrast medium showing a well-enhanced mass located in the left parietal bone.

The tumor was totally removed by left parietal craniotomy on December 2, 1994. The lesion was considered to be malignant, so a wider skin incision outside the abnormal scalp was employed to approach the mass. The epidermis appeared edematous and partially reddened. The subcutaneous tissue was not necrotic, and the galea was recognizable and not separable from the calvarial mass. The osseous tumor blended with a thickened pericranium at the periphery. The bulk of the tumor was grayish, not encapsulated, and extremely friable. The tumor had penetrated the dural membrane into the cortex. It was mostly circumferentially lifted from the brain. No undue endeavor was made to pursue the intracerebral invasion as the central sulcus might have
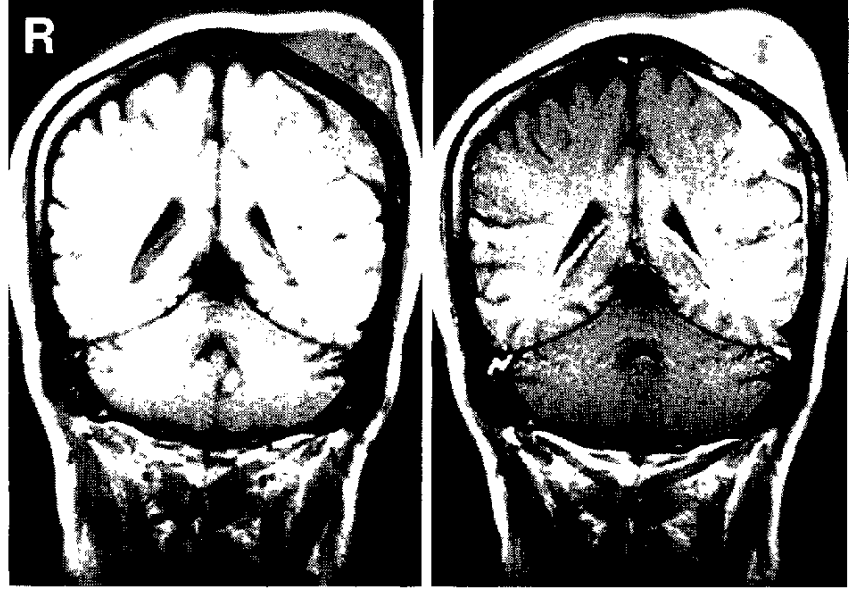

Fig. 3 Magnetic resonance images without (left) and with (right) gadolinium indicating the mass in the parietal bone with extension into the brain, associated with slight compression. The tumor margin with the adjacent cortical surface was not clarified.

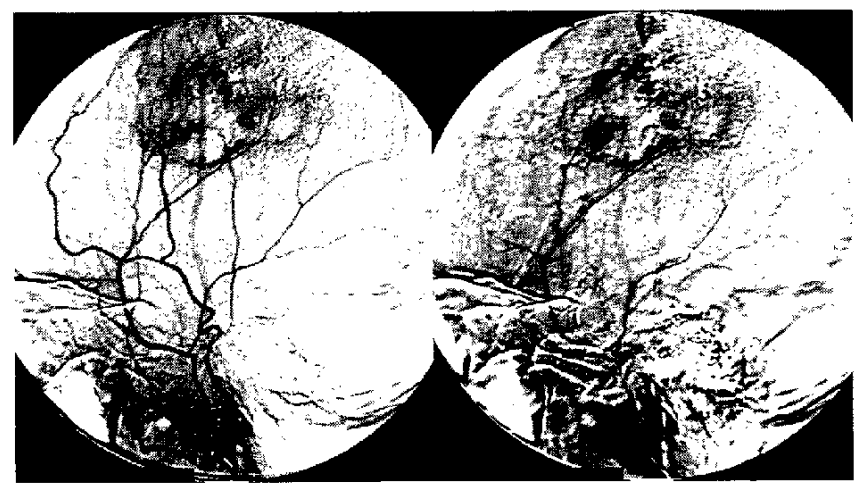

Fig. 4 Selective external carotid angiograms showing the vascular-rich skull tumor fed by the superficial temporal and meningeal medial arteries.

been involved. The larger calvarial defect was surrounded by multiple punctuate bony craters produced by the neoplastic process. The dural membrane that was thickened and infiltrated by the cranial tumor was repaired dural plasty using an artificial dural membrane.

Histological examination found that the tumor had infiltrated into the Virchow-Robin space and consisted of scattered small hyperchromatic cells and large, bizarre, and multinucleated cells which suggested a histiocytic origin. Some areas consisted of fusiform cells displaying a typical storiform pattern (Fig. 5). Mitotic activity was evident. Wide areas of necrosis were also present. Staining with $\alpha_{1}$-an- 


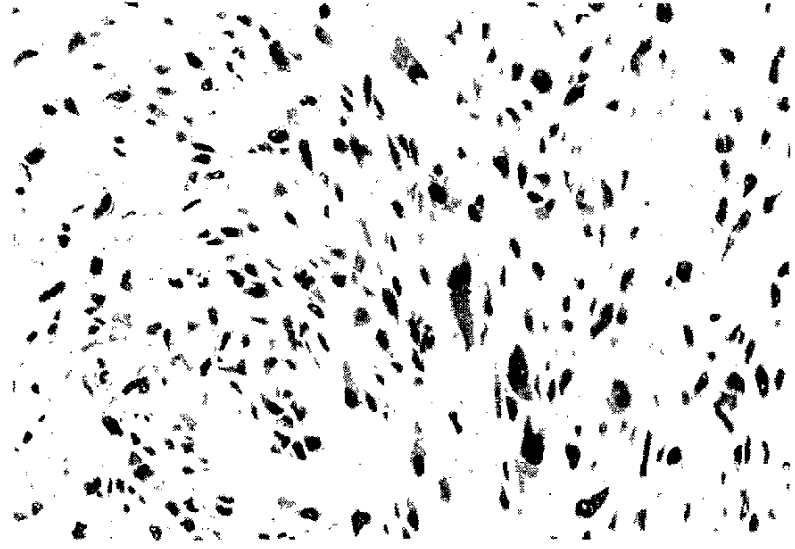

Fig. 5 Photomicrograph showing tumor cells consisting of scattered small hyperchromatic cells and large, bizarre, and multinucleated cells suggesting a histiocytic origin, and fusiform cells displaying a typical storiform pattern in some areas. Mitotic activity is evident. Wide areas of necrosis are also present. HE stain, $\times 200$.

titrypsin was positive, but $\mathrm{kp}-1, \mathrm{~S}-100$ protein, and osteocalcin were negative. The diagnosis was $\mathrm{MFH}$ of the storiform, pleomorphic, variant type.

The preoperative complaint of sensitivity to touch was completely relieved by the operation. Additional postoperative investigations including CT and MR imaging of the whole body excluded neoplastic disease elsewhere. The patient received $59.5 \mathrm{~Gy}$ of irradiation to the surgical site and was treated with two courses of CHOP chemotherapy (cyclophosphamide [Endoxan; Shionogi \& Co., Ltd., Osaka] $750 \mathrm{mg} / \mathrm{m}^{2}$, doxorubicin [Adriacin; Kyowa Hakko Kogyo Co., Ltd., Tokyo] $50 \mathrm{mg} / \mathrm{m}^{2}$, vincristine [Oncovin; Shionogi \& Co., Ltd.] $1.4 \mathrm{mg} / \mathrm{m}^{2}$, and prednisolone [Predonin; Shionogi \& Co., Ltd.] 50 mg for 5 days, consequently $40 \mathrm{mg}$ for 3 days, $20 \mathrm{mg}$ for 3 days, and finally $10 \mathrm{mg}$ for 3 days). Postoperative neurological defects were moderate hypalgesia of the second to fourth fingers of the right hand.

The patient was discharged on February 16, 1995. Cranioplasty with artificial bone was performed on July 7, 1995. Follow-up MR imaging and CT findings up to April 1997 have detected no evidence of recurrence or metastasis to other organs.

\section{Discussion}

Eight cases of MFH primarily affecting the skull bones including the present case have been reported (Table 1)..$^{3-6,9,10,12]}$ Patients were aged from 2.5 to 72 years. There were five males and three females. No sex predominance was observed. Seven patients presented with a rapidly enlarging mass on the skull without associated pain. Our case was the only one located in the parietal bone. All patients demonstrated intracranial extension of the tumor associated with the extracranial vault. A 2.5-year-old infant presented with an osteolytic retropharyngeal mass arising from the clivus. ${ }^{4)}$

MFH is defined as usual in the differential diagnosis of a pleomorphic sarcoma. ${ }^{11)} \mathrm{MFH}$ consisting of histiocytic and fibroblastic cells belongs to a group of soft-tissue tumors with a common histogenesis from undifferentiated mesenchymal cells. ${ }^{13)}$ The cells are arranged in a storiform pattern. ${ }^{10,11,14)}$ Histological diagnosis of this tumor may be difficult based only on light microscopy as many of the features are not entirely specific. Positive staining for $\alpha_{1}$-antitrypsin and $\alpha_{1}$-antichymotrypsin using the immunoperoxidase techniques are absent in fibrosarcoma, liposarcoma, or spindle-cell carcinoma. ${ }^{1)}$ These are useful and specific markers for MFH. In our case, histological studies indicated the presence of pleomorphic spindle cells in a storiform pattern and positive reactions for $\alpha_{1}$-antitrypsin. These findings were highly suggestive of the histiocytic origin of the

Table 1 Summary of cases of malignant fibrous histiocytoma in the cranium

\begin{tabular}{|c|c|c|c|c|}
\hline Author (Year) & Age/Sex & Location & Treatment & Outcome \\
\hline Chiatle et al. $(1981)^{3)}$ & $18 / \mathrm{M}$ & temporal & $\begin{array}{l}\text { surgery, radiation therapy, } \\
\text { chemotherapy }\end{array}$ & alive $(1 \mathrm{yr})$ \\
\hline Dyck $[1987]^{5]}$ & $41 / \mathrm{M}$ & frontal & surgery, radiation therapy & alive $(8 \mathrm{mos})$ \\
\hline Cook et al. $(1987)^{4)}$ & $2.5 / \mathrm{M}$ & clivus & $\begin{array}{l}\text { surgery, radiation therapy, } \\
\text { chemotherapy }\end{array}$ & $\begin{array}{l}\text { died ( } 3.5 \text { yrs of } \\
\text { recurrence) }\end{array}$ \\
\hline Romero et al. (1989) ${ }^{12\}}$ & $37 / \mathrm{F}$ & temporal & surgery & alive \\
\hline Matuura et al. $(1991)^{9)}$ & $72 / \mathrm{M}$ & occipital & surgery & died (6 mos) \\
\hline Hatashita et al. $(1992)^{6)}$ & $45 / \mathrm{M}$ & frontal & surgery & alive [2 yrs] \\
\hline Nakayama et al. $(1997)^{10}$ & $19 / F$ & temporal & surgery, chemotherapy & died (4 days) \\
\hline Present case & $45 / F$ & parietal & $\begin{array}{l}\text { surgery, radiation therapy, } \\
\text { chemotherapy }\end{array}$ & alive $(2.5 \mathrm{yrs}$ ) \\
\hline
\end{tabular}


tumor cells and the final diagnosis of MFH could be confidently made.

All reported patients underwent gross total removal of the tumor because of its aggressive nature. Our patient received extensive surgical removal including resection of the bone edge and bulging tumor into the brain, followed by irradiation and chemotherapy. MFH frequently metastasizes during its course, most commonly to the lung in contrast to fibrosarcoma or osteosarcoma. The prognosis for MFH occurring in the skull bones is miserable, like MFH in other sites of the body, with a survival for 3.5 years at most (Table 1).

The chemotherapy regimen to treat tumors of histiocytic origin has not yet been established. We employed CHOP therapy consisting of cyclophosphamide, doxorubicin, vincristine, and prednisolone, as recommended previously. ${ }^{3,8)}$ In our case, radiation therapy was given soon after the operation and chemotherapy. Two and half a years later, no metastasis and recurrence has occurred.

\section{References}

1) Boulay CEH: Demonstration of alpha-1-antitrypsin and alpha-1-antichymotrypsin using the immunoperoxidase technique. Am J Surg Pathol 6: 559564,1982

2) Capanna R, Bertoni F, Bacchini P, Bacci G, Guerra A, Campanacci M: Malignant fibrous histiocytoma of bone. Cancer 54: 177-187, 1984

3) Chiatle VS, Sundaresan N, Helson L, Huvos A: Malignant histiocytoma of the temporal bone with intracranial extension. Acta Neurochir (Wien) 59: 239246,1981

4) Cook BR, Vries JK, Martinez AJ: Malignant fibrous histiocytoma of the clivus: Case report. Neurosurgery 20: 632-635, 1987

5] Dyck P: Malignant histiocytoma of the pericranium.
Case report. Acta Neurochir (Wien) 86: 61-64, 1987

6) Hatashita $\mathrm{S}$, Tajima A, Ueno $\mathrm{H}$ : Malignant fibrous histiocytoma in the skull. Case report. Neurol Med Chir (Tokyo) 32: 976-979, 1992

7) Jee A, Domboski M, Milbosky SA: Malignant fibrous histiocytoma of the maxilla presenting with endodontically involved teeth. Oral Surg 45: 464-469, 1987

8) Leite C, Goodwin JW, Sinkovicgs JG, Baker LH, Benjamin R: Chemotherapy of malignant fibrous histiocytoma. A Southwest Oncology Group report. Cancer 40: 2010-2014, 1977

9) Matuura S, Takagi T, Tan EC, Mizuno S, Imagunbai N, Hasegawa R: Malignant fibrous histiocytoma of the occipital bone with intracranial extension. Neurol Med Chir (Tokyo) 31: 219-222, 1991

10) Nakayama $K$, Nemoto $Y$, Inoue $Y$, Mochizuki $T$, Soares SB Jr, Ohata K, Katsuyama J, Onoyama Y, Wakasa K: Malignant fibrous histiocytoma of the temporal bone with endocranial extension. AJNR Am J Neuroradiol 18: 331-334, 1997

11) O'Brien JE, Stout AP: Malignant fibrous histiocytoma. Cancer 17: 1445-1455, 1964

12) Romero F, Ortega A, Ibarra B, Piqueras J, Rovira M: Post-radiation cranial malignant fibrous histiocytoma studied by CT. Comput Med Imaging Graph 13: 191-194, 1989

13) Singh B, Shara A, Har-El G: Malignant fibrous histiocytoma of the head and neck. J Craniomaxillofac Surg 21: 262-265, 1993

14) Taxy JB, Battifora $H$ : An electron microscopic study. Cancer 40: 254-257, 1977

15) Weiss SW, Enzinger FM: Malignant fibrous histiocytoma. An analysis of 200 cases. Cancer 41: 22502266, 1978

Address reprint requests to: D. Yoshida, M.D., Department of Neurological Surgery, Nippon Medical School, 11-5 Sendagi, Bunkyo-ku, Tokyo 113-0022, Japan. 